مهارات إنتاج الاروس الإكترونية باستخدام برنامج

\title{
Articulate Storyline3
}

\author{
د) \\ إعـ \\ أ نصر الدين مبروك
}

باحث دكتوراه تكنولوجيا التعليم كلية التربية النوعية - جامعة المنيا

د/ وفاء صلاح الدين إبراهيم

أستاذ تكنولوجيا التعليم كلية التربية النوعية- جامعة المنيا

$$
\text { أ.م.د/ ممدوح عبد الحميد ابراهيم }
$$

استاذ تكنولوجيا التعليم المساعد- كلية التربية النوعية - جامعة المنيا

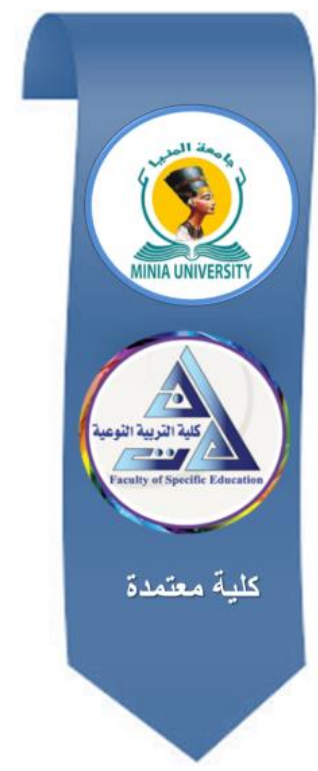

\section{مجلة البحوث في مجالاث التربية التوعية}

معرف البحث الرقمي DOI: 10.21608/jedu.2020.49175.1121

$$
\text { المجلد السابع العدد } 32 \text { ـ يناير } 2021
$$

\section{P-ISSN: 1687-3424 IS- ISSN: 2735-3346}

https://jedu.journals.ekb.eg/ موقع المجلة عبر بنك المعرفة المصري

http://jirfse.minia.edu.eg/Hom موقع المجلة العنوان: كلية التربية النوعية ـ جامعة المنيا ـ جمهورية مصر العربية

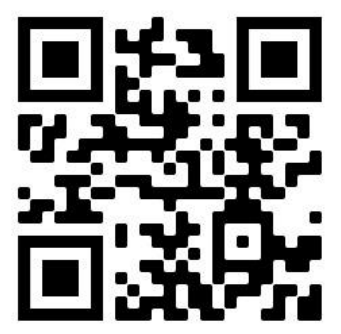


مجلة البحوث فى مجالات التربية النوعية 
مهارات إنتاج الاروس الإكترونية باستخدام برنامج

\section{Articulate Storyline3}

أ/ نصر الدين مبروك، د/ وفاء صلاح الدين إبراهيم، أ.م.د/ ممدوح عبد الحميد ابراهيم

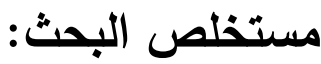

أصبحت الدروس الإكترونية مطلب ضروري في ظل جائحة كرونا لجميع

المتعلمين في المراحل الدراسية المختلفة، وهو ما يستلزم تتمية مهارات تصميمها وإنتاجها

لاى طلاب وأخصائيي تكنولوجيا التعليم، وقد أشارت الأدبيات إلى أن تحديد المهارات التي تمكنهم من إنتاجهم له دور كبير في تحقيق الأهداف التعليمية المرجوة من تلك الدروس. ولهذا سعي هذا البحث إلى تحديد قائمة بمهارات إنتاج الدروس الإلكترونية بإستخدام برنامج Articulate Storyline3، وقد استخدم الباحثون لتحقيق هذا الهدف المنهج الوصفي التحليلي لإشتقاق بنود القائمة، وتم بناء القائمة من خلال الاطلاع على بلى ولى بعض الدراسات والبحوث والأدبيات المرتبطة بإنتاج المحتوى الإلكتروني والدروس باء باء الإلكترونية، وكذللك تمت الاستعانة بآراء بعض الخبراء في مجال التعلم الإلكتروني، وأيضا من خلال تحليل العمل، ومراجعة معايير تصميم وإنتاج المقررات الإكترونية الموضوعة من قبل المركز القومي للتعلم الإلكتروني بمصر، وتم عرض القائمة على ولى مُحكمين من أساتذة تكنولوجيا التعليم والخبراء في المجال وإجراء التعديلات المقترحة Articulate لتصبح قائمة بمهارات إنتاج الدروس الإلكترونية بإستخدام برنامج Storyline3 مهارة فرعية. الكلمات الدالة: المهارات، الدروس الإككترونية، مهارات إنتاج الدروس الإلكترونية 


\section{Skills of producing e-lessons using Articulate Storyline3}

\section{Summary of the research:}

E-lessons have become a necessary requirement in light of the Corona pandemic for all learners in different school stages, which necessitates the development of their design and production skills among students and education technology specialists, and the literature has indicated that identifying the skills that enable them to produce them has a great role in achieving the desired educational goals of these lessons. That is why this research sought to identify a list of the skills of producing e-lessons using the Articulate Storyline3 program. To achieve this goal, the researchers used the descriptive and analytical approach to derive the list items. The list was built by reviewing some studies, research and literature related to the production of e-content and e-lessons. With the opinions of some experts in the field of e-learning, and also through work analysis, reviewing the standards for designing and producing electronic courses developed by the National E-Learning Center in Egypt, and the list was presented to referees of educational technology professors and experts in the field and proposed amendments to become a list of e-lesson production skills Using the Articulate Storyline3 program, in its final form, consisting of (9) basic skills, of which (66) sub-skills are included.

Key words: Skills, e-lessons, Skills of producing Elessons. 


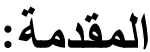

تتصف نظم التعليم الحالية بأنها رقمي أو إلكترونبة، ولقد سارعت المؤسسات التعليمية بتطوير أنظمتها التعليمية لمواكبة التطور السريع المتلاحق في التقنية وما صاحبه من انعكاسات على العلية التعليمية التى تتأثر بأي تغير في المجتمع وتؤثر فيه.

وتُحد المقررات والدروس الإلكترونية إحدي مستحدثات هذه التكنولوجيا الحديثة وإستخدام الكمبيوتز وتطبيقاته في العطلية التعليمية، وأصبح من الضرورة الإهتمام بإنتاج هذه الدروس الإلكترونية وتتميتها لاى متخصصي تكنولوجيا التعليم والتي تتعكس فائدتها على المجتمع الطلابي والمعلمين بالمدرسة وتزيد من التفاعل والإيجابية بين الطلاب بعضهم البعض.

وقد أكدت عديد من الدراسات على أهمية تصميم الدروس الإلكترونية وإنتاجها، منها: دراسة أحمد محمد أحمد (2017) * التي هدفت إلى التعرف على المهارات اللازمة لإتناج الدروس الإلكترونية التفاعلية متعددة الوسائط لدى طلاب تكنولوجيا التعليم، وقد أثنارت نتائج الدراسة إلى توصل الباحث إلى إعداد قائمة بالمهارات اللازمة لإنتاج برمجيات الدروس الإكترونية التفاعلية متعددة الوسائط، ودراسة أحدد عبداله محمود (2012) التي استهافت إلى التعرف على فعالية إستخدام المدونات الإكترونية في تتمية مهارات إنتاج الدروس الإلكترونية لاى متخصصي تكنولوجيا التعليم، وقد أثنارت نتائج الدراسة إلى فعالية إستخدام المدونات الإككترونية في تتمية مهارات إنتاج

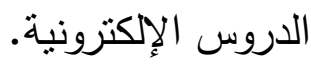

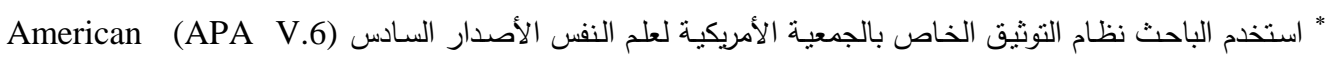
Psychological Association 


\section{الإحساس بمشكلة البحث والتتأكد منها:}

حدد الباحث مشكلة البحث من خلال المصادر الآتية: - عمل الباحث كمدير لإدارة التعليم من بُعد بوزارة التربية والتعليم، ومن مهامه الإثراف والمتابعة أثناء إنتاج المحتوى الإلكتروني للفصول الافتراضية (منصة البث المباشر بوزارة التربية والتعليم) حيث يقوم أخصائي تكنولوجيا التعليم العاملون باستوديوهات البث بمحافظات الجمهورية- ومعظمه من خريجي أقسام تكنولوجيا التعليم بكليات التربية النوعية- بتصميم وإنتاج المحتوى بلون الإلكتروني الذي يقدم من خلا الفصول الإفتراضية، وقد لاحظ الباحث قصور واضح في مهاراتهم التصميمية والإنتاجية، بالإضافة إلى إستخدامهم برنامج

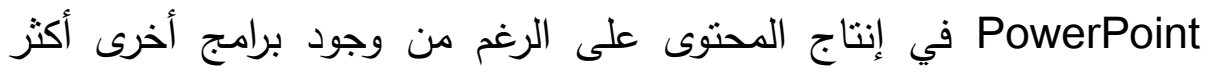
ملائمة وجودة؛ فتأكد لدى الباحث مدى أهمية إلمام طلاب تكنولوجيا التعليم بمهارات تصميم وإنتاج الدروس الإلكترونية للفصول الافتراضية لجميع المراحل الدراسية؛ حتى يتسنى لهم القيام بالدور المنوط بهم. - توصيات المؤتمرات، حيث جاءت توصيات المؤتمر الدولي للتعلم الإلكتروني والتعليم عن بُعد على مدار ثناثة أعوام منتالية (2013)، (2014)، (2015) بضرورة تتمية مهارات تصميم وإنتاج المحتوى الإلكتروني، كما أوصت أيضًا بأهمية اتجاه بحوث تكنولوجيا التعليم إلى إعداد المعلمين وتتمية كفاياتهم المهنية لتتمل هذه النوعية الجديدة من متطلبات دورهم في مجال التعلم الإلكتروني. تحديد مشكلة البحث:

مما سبق عرضه تم تحديد مشكلة البحث فىى: الحاجة إلى قائمة بمهارات إنتاج الدروس الإكترونية بإستخدام برنامج Articulate Storyline3. أسئلة البحث: أمكن معالجة مشكلة هذا البحث من خلال الإجابة على السؤال الآتي: 
كيف يمكن إعداد قائمة بمهارت إنتاج الدروس الإككترونية بإستخدام برنامج Articulate

؟Storyline 3

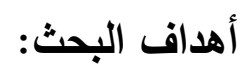

هدف هذا البحث إلى التوصل إلى قائمة بمهارت إنتاج الدروس الإلكترونية

بإستخدام برنامج Articulate Storyline3. أهمية البحث:

من المتوقع أن يفيد هذا البحث المطورون التعليميون والمعلمون المنتجون لاروسهم والطلاب في توفير قائمة مهارات إنتاج الدروس الإلكترونية باستخدام برنامج .Articulate Storyline3

$$
\text { محددات البحث: }
$$

اقتصر هذا البحث على استخلاص مهارات إنتاج الدروس الإكترونية باستخدام برنامج Articulate Storyline3 من الدراسات والبحوث والأدبيات المرتبطة والتي أمكن الحصول عليها، وأيضا من تحليل العمل، ثم عرضها على مجموعة من المحكمين

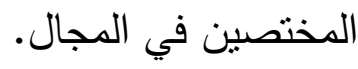

$$
\text { منهج البحث: }
$$

استخدم الباحث منهج البحث الوصفي التحليلي.

$$
\text { خطوات البحث: }
$$

سار هذا البحث وفق الخطوات التالية:

- مراسـة مسـحية تحليليـة للأدبيـات والدراسـات المرتبطـة بموضـوع البحث؛ وذلك بغـرض إعـداد قائمـة بمهـارات إنتـاج الــروس الإككترونيـة بإسـتخدام برنـامج

.Articulate Storyline3 
- - إعداد الصيغة الأولية لقائمة مهارات إنتاج الدروس الإلكترونية بإستخدام برنامج

.Articulate Storyline3

- عرض قائمة المهارات في صورتها الأولية على مجموعة من أساتذة تكنولوجيا التعليم والخبراء المستخدمين للبرنامج، ثم تعديلها في ضوء آرائهم وملاحظاتهم

واقتراحاتهم لتصبح في صورتها النهائية.

- - التوصل إلى الصورة النهائية لقائمة المهارات.

مصطلحات البحث:

المهارات "Skills" (المهات

عرفها الباحث إجرائيًا بأنها "مجموعة المعارف والخبرات والقدرات الثخصية التي يجب توافرها عند مستخدم برنامج Articulate Storyline3 والتي تمكنه من إنتاج

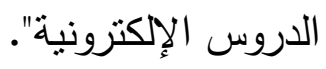

$$
\text { الارس الإلكتروني "E- lesson": }
$$

Articulate عرفها الباحث إجرائيًا بأنها "برنامج تعليمي مُنتج باستخدام برنامج Storyline3، يشتمل علي وسائل متعددة تتمنل في نصوص ورسومات وصور وأصوات ومقاطع فيديو، كما يشتمل على تغذية راجعة وتقويم، وأيضا أدوات للإبحار

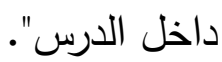

مهارات إنتاج الدروس الإلكترونية "Skills of producing E- lessons": عرفها الباحث إجرائيًا بأنها "جميع الأداءات التي يقوم بها الطالب لإنتاج درس إلكتروني باستخدام برنامج Articulate Storyline3، ويحتوى الدرس على نصوص ورسومات وصور وأصوات ومقاطع فيديو، كما يشتمل على تغذية راجعة وتقويم، وأيضا

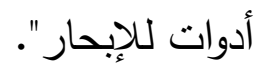


الإطار النظري والدراسات السابقة:

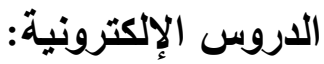

تُعرف الدروس الإلكترونية على أنها: "دروس تُستخدم في تصميمها أنشطة ومواد تعليمية تعتمد على الحاسوب وشبكات المعلومات في تقديم محتوى غني بمكونات الوسائط المتعددة التفاعلية تحقق إيجابية المتعلم ومثاركته" (إبراهيم عبدالوكيل الفار، سعاد أحمد شاهين،2001،40-41)، كما يُعرف حلمي أبو الفتوح عمار (2007، (19) الدرس الإلكتروني على أنه "برنامج تعليمي يرتكز على الوسائط المتعددة والفائقة ويستخدم خصائص ومصادر الويب بغرض تقديم تعلم ذا معنى، حيث يُسرع خُطى

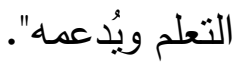

برامج إنتاج الاروس الإكترونية:

توجد عديد من البرامج التي يمكن استخدامها في إنتاج الدروس والمقررات

الإلكترونية منها على سبيل المثال: PowerPoint, Lecture Maker, Adobe ‘Easy generator, Captivate, Rapitvity, I spring, Articulate Storyline وقد استخدم الباحث برنامج Articulate Storyline3 لما بتسم به البرنامج من خصائص تميزه عن أدوات تأليف ونشر الدروس والمقررات الإكترونية الآخرى، وهى: - سهولة استخدام واجهة المستخدم. - - يوفر قوالب جاهزة عديدة يمكن استخدامها في بناء الإختبارات الإلكترونية؛ أتاح مرونة في تصميم الإختبارات الإلكترونية. - - يوفر شخصيات منتوعة مدمجة في البرنامج حيث يمكن الإستفادة منها في شرح الدروس والمقررات الإلكترونية. - القدرة على استيراد المحتوى من المشروعات والتطبيقات الأخرى. - يتيح التقاط الصورة من شاشة سطح المكتب Screenshot. 
- سهولة التفاعل عبر استخدام المشغلات Triggers والمتغيرات والثريط الزمني

$$
\text { وطبقات الشرائح. }
$$

- - تسجيل لقطات الفيديو مباشرة دون الحاجة إلى أدوات وبرامج أخرى. - - يدعم البرنامج اللغة العربية.

- - مشاركة القوالب التفاعلية وسهولة إضافة خاصيتي السحب والإفلات التفاعلية. - - - إمكانية نشر الدروس بصيغ متعددة.

\section{مهارات إنتاج الاروس الإكترونية:}

تعددت تعريفات المهارة بتعدد مصادر دراستها، وطرق أدائها فقد عرفها أحمد

حسين اللقاني (187،1999) بأنها "الأداء السهل الدقيق القائم على الفهم لما بتعلمه الإنسان حركيًا وعقليًا مع توفير الوقت والجهد والتكاليف"، وعرفتها أيضًا سهيلة محسن الفتلاوي (2003، 25) بأنها "ضرب من الأداء تُعلم الفرد أن يقوم به بسهولة وكفاءة ودقة مع إقتصاد في الوقت والجهد سواء أكان الأداء عقليًا أو إجتماعيًا أو حركيًا". أنثار كل من كوثر حسين كوجك (2001،268)، وفؤاد عبداللطيف أبو حطب، آمال مُختار صادق (1999،2489) إلى أن لمهارات الإنتاج عديد من الجوانب، وهي

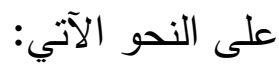

- - جانب عقلي (معرفي) في المهارة: تُعد المهارة نوعًا من أنواع التعلم، وهي تتطلب جوانب معرفية وعمليات عقلية، فأول مستويات تعلم المهارة هو الإعداد لتعلمها، ويدخل ضمن العمليات العقلية الخاصة بها، وبالتالي فالمهارة لا تعتبر نشاطًا حركيًا فحسب، بل إن لها جانبًا آخر هو الجانب العقلي المعرفي، وبعني القدرة على استخدام المعرفة بفاعلية وسهولة في موقف الأداء. - - جانب أدائي (سلوكي) في المهارة: وهو الجانب العملي الذي يخضع للملاحظة من قبل المتعلم، ويكون في صورة خطوات وأفعال سلوكية، ويمكن التمييز بين نوعين من الأداء هما: الأداء العادي وهو يمثل الحد الأدني من الإنجاز الفعلي 
الذي يقوم به الفرد، والأداء الماهر وهو يمثل مستوى عالٍ من الإنجاز الفعلي للفرد، ويتميز هذا الأداء الماهر عن الأداء العادي بالسرعة والدقة والمرونة والثقة وعدم الإرتباك وقلة الأخطاء والتكيف في العمل والجودة، فهو الأداء الذي تظهر فيه خصائص المهارة. - - جانب وجداني (إنفعالي) في المهارة: وهو الذي يتصل بالإحساس وبالإنفعال ولا يقل هذا الجانب عن الجانبين السابقين، ويُعد من أهم موجهات السلوك الإنساني وهذا الجانب يمكن تعديله وتغييره شأنه في ذلك شأن الجوانب الأخرى للسلوك الإنساني، وبالتالي فهو يرتبط في علاقة عضوية بالجوانب الأخرى.

تتقسم مهارات إنتاج الدروس الإكترونية إلى مهارات ترتبط بتحضبر خطة الدرس، وهي مهارات عامة في تصميم الدروس الإلكترونية بصرف النظر عن التقنية المستخدمة، ومهارات خاصة أو مهارات تقنية ترتبط بإنتاج الدروس. - وقد أوصت عديد من الدراسات بضرورة الإهتمام بتتمية مهارات أخصائيي تكنولوجيا التعليم والمعلمون في مجال التعلم الإلكتروني وخاصة إنتاج الدروس الإكترونية، ومن هذه الدراسات دراسة سلامة عبد العظيم حسن، وأثنواق عبدالجليل علي (2008) والتي أكدت على ضرورة عقد دورات تدريبية للمعلمين وأخصائيي تكنولوجيا التعليم في أثثاء الخدمة على إعداد المقررات الإكترونية

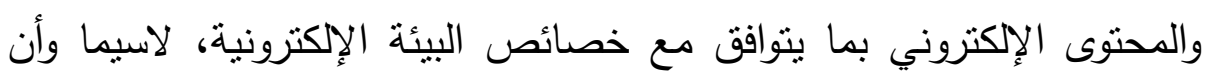
لكلًا من المعلم وأخصائي تكنولوجيا التعليم أدوار في ظل التعلم الإكتروني لإني ذكرها كلًا من محمد عطية خميس (2009، 98)، زينب محمد أمين(2008، 18)، منها:

- - تصميم وإنتاج الدروس والمقررات الإلكترونية متعددة الوسائط. - - إنشاء المواقع وتصميم ونشر الدروس الإلكترونية عبر وسائل النشر المختلفة. 


\section{إجراءات البحث:}

قام الباحثون بإعداد قائمة بمهارات إنتاج الدروس الإكترونية باستخدام برنامج Articulate Storyline3

- تحديد الهـف من القائمة: هدفت القائمة في صورتها الأولية إلى تحديد مهارات

إنتاج الدروس الإككترونية باستخدام برنامج Articulate Storyline3.

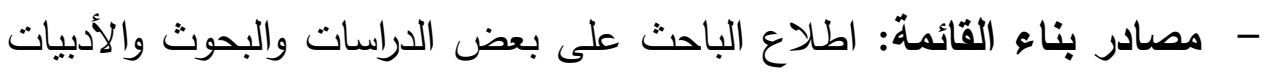

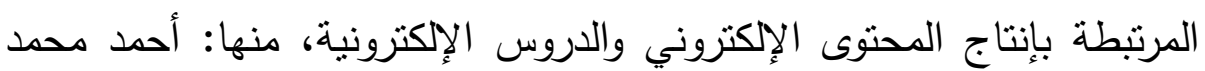

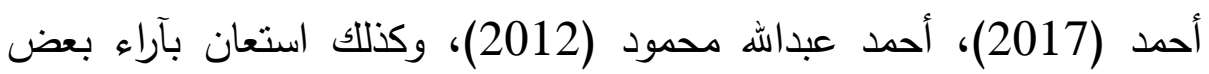

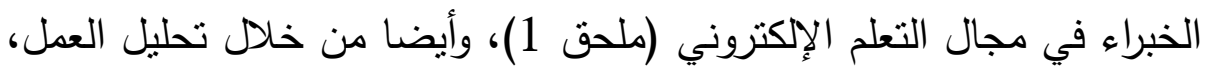
ومراجعة معايير تصميم وإنتاج المقررات الإككرونية الموضوعة من قبل المركز القومي للتعلم الإلكتروني بمصر • مدرابر

\section{صياغة مفردات قائمة المهارات في صورتها الأولية:}

اشتملت قائمة المهارات في صورتها الأولية على (9) مهارات رئيسة يندرج تحتها

$$
\text { (75) مهارة فرعية، وهي موزعة كما بالجدول الآتي: }
$$

جدول (1)

توزيع مهارات إنتاج الاروس الإكترونية باستخدام برنامج

Articulate Storyline3

\begin{tabular}{|c|c|c|}
\hline عدد المهارات الفرعية & المهارات الأساسية & b \\
\hline 8 & مهارات التعامل مع الثرائح. & 1 \\
\hline 10 & مهارات التعامل مع النصوص. & 2 \\
\hline 9 & مهارات التعامل مع الصور والرسومات. & 3 \\
\hline 9 & مهارات التعامل مع مقاطع الصوت والفيديو والفلاش. & 4 \\
\hline 6 & مهارات التعامل مع الملفات الخارجية. & 5 \\
\hline 10 & مهارات التعامل مع الأثَكال والكائنات التفاعلية. & 6 \\
\hline 8 & 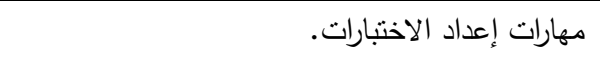 & 7 \\
\hline 10 & 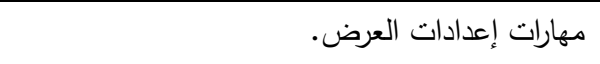 & 8 \\
\hline 5 & مهارات النشر الإلكتروني. & 9 \\
\hline 75 & & 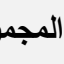 \\
\hline
\end{tabular}


- التأكد من صلاحية قائمة المهارات:

عرضت قائمسة المهارات في صورتها الأولية على (6) من المتخصصين في

مجال التعلم الإكتروني عامة وتطوير المقررات الإكترونية على وجه الخصوص، و (6) من مطوري المقررات الإلكترونية بمراكز إنتاج المقررات الإلكترونية بالجامعات المصرية المسـتخدمون لبرنـامج Articulate Storyline3 (ملـق 1)؛ للتنأكد مـن صـدقها الظاهري، وابداء آرائهم، وملاحظاتهم حولها، ويوضح شكل (1) استمارة التحكيم:

\begin{tabular}{|c|c|c|c|c|}
\hline \multirow{2}{*}{ تعديلات مقترحة } & \multicolumn{2}{|c|}{ مدى أهمية المهارة } & \multirow{2}{*}{ المهارة } & \\
\hline & غير مهمة & مهمة & & r \\
\hline
\end{tabular}

شكل (1) استمارة تحكيم قائمة مهارات إنتاج الاروس الإكترونية

\section{Articulate Storyline3 باستخدام برنامج}

بعد تلقي الباحث لآراء وتعليقات المحكمين على قائمة المهارات قام بإجراء

التعديلات التي اتفق المحكمون على ضرورة تعديلها، فتم حذف (9) مهارات فرعية، وتعديل صياغة بعض المهارات، ويظهر ذلك في الجدول الآتي:

جدول (2)

يوضح تعديلات المحكمين على قائمة مهارات إنتاج الدروس الإكترونية

Articulate Storyline3 باستخدام برنامج

\begin{tabular}{|c|c|c|c|c|}
\hline المهارة المراد حذفها & م & المهارة بعد التعديل & المهارة قبل التعديل & م \\
\hline بُوظف الصور داخل المُحتوى & $1 / 3$ & شُحاذي النص (يمين، وسط، & 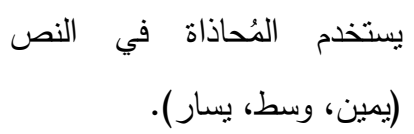 & $6 / 2$ \\
\hline يتجنب الصور كثيرة التفاصيل. & $2 / 3$ & يُضيف تعداد رقمي للنص. & يعمل تعداد نقطي ورقمي للنص. & $7 / 2$ \\
\hline يستخدم صورًا تعبر عن مضمون الدرس الإلكتروني. & $3 / 3$ & يُضيف خلفية لمربع النص. & يعمل خلفية لمربع النص. & $8 / 2$ \\
\hline يجعل مساحة الصورة أو الرسم أو & $4 / 3$ & يُضيف إطار للصورة. & يقوم بعمل إطار للصورة. & $6 / 3$ \\
\hline
\end{tabular}


مجلة البحوث في مجالات التربية النوعية

\begin{tabular}{|c|c|c|c|c|}
\hline المهارة المراد حذقها & م & المهارة بعد التعديل & المهارة قبل التعديل & b \\
\hline العناصر الأخرى. & & & & \\
\hline بمُحتخدى الدرس. اللقطات وثيقة الصلة & $1 / 4$ & يُغير حجم الصورة. & يقوم بتغيير حجم الصورة. & $7 / 3$ \\
\hline بدرج مقطع فلاش داخل الثريحة. & $4 / 4$ & ليُضيف أدوات التحكم في عرض الفيديو. & الفيديو وإعادتها عند الحاجة. عرض لقطات & $6 / 4$ \\
\hline داخل الثريحة. مقطع الصوت الموجود & $5 / 4$ & والصُورة. التزامن بين الصوت & يُراعى التزامن بين الصوت & $8 / 4$ \\
\hline فيدنبو داخل الثناثة. أكثر من مقطع & $7 / 4$ & يُغنير في أنماط الأزرار. & 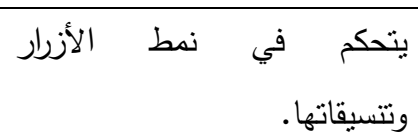 & $3 / 5$ \\
\hline \multirow[t]{6}{*}{ التعزيز الإيجابي والاختلاف بين أصوات } & $9 / 4$ & يُغير لون الثُكل داخل الثُريحة. & الثريحة. بتغيير لون الثكل داخل & $2 / 6$ \\
\hline & & يُدرج سؤالاً من نمط الاختيار من & متعدد سؤالاً من نمط الاختبار من & $1 / 7$ \\
\hline & & يُدرج سؤالاً من نمط الترتيب. & يُعد سؤالاً من نمط الترتيب. & $2 / 7$ \\
\hline & & يُدرج سؤالاً من نمط التوصيل. & يُعد سؤالاً من نمط التوصيل. & $3 / 7$ \\
\hline & & يُغير في ألوان وتأثثرات المُشغل. & ليتحكم في ألوان وتأثيرات & $9 / 8$ \\
\hline & & يُغير في إعدادات اليُستعرض. & يتحكم في إعدادات المُستعرض. & $10 / 8$ \\
\hline
\end{tabular}

ويوضـح جدول (3) النسـب المئويـة لاتقـاق آراء المحكمين على مدى أهميـة

المهارة بالنسبة للفئة المستهدفة: 
مجلة البحوث في مجالات التربية النوعية

جدول (3)

النسب المئوية لاتفاق آراء المحكمين على مدى أهمية المهارة بالنسبة للفئة المستهدفة

\begin{tabular}{|c|c|c|c|c|c|c|c|c|c|}
\hline \multicolumn{4}{|c|}{ أهمية المهارة الفرعية بالنسبة للفئة المستهدفة } & \multirow{3}{*}{ p } & \multicolumn{4}{|c|}{ أهمية المهارة الفرعية بالنسبة للفئة المستهدفة } & \multirow{3}{*}{ P } \\
\hline \multicolumn{2}{|c|}{ غير مهمة } & \multicolumn{2}{|c|}{ مهمة } & & \multicolumn{2}{|c|}{ غير مهمة } & \multicolumn{2}{|c|}{ مهمة } & \\
\hline النسبة & تكرار & النسبة & تكرار & & النسبة & تكرار & النسبة & تكرار & \\
\hline- & - & $\% 100$ & 12 & 39 & - & - & $\% 100$ & 12 & 1 \\
\hline- & - & $\% 100$ & 12 & 40 & - & - & $\% 100$ & 12 & 2 \\
\hline- & - & $\% 100$ & 12 & 41 & - & - & $\% 100$ & 12 & 3 \\
\hline- & - & $\% 100$ & 12 & 42 & $\% 8.3$ & 1 & \%91.7 & 11 & 4 \\
\hline- & - & $\% 100$ & 12 & 43 & - & - & $\% 100$ & 12 & 5 \\
\hline- & - & $\% 100$ & 12 & 44 & - & - & $\% 100$ & 12 & 6 \\
\hline- & - & $\% 100$ & 12 & 45 & $\% 8.3$ & 1 & \%91.7 & 11 & 7 \\
\hline- & - & $\% 100$ & 12 & 46 & - & - & $\% 100$ & 12 & 8 \\
\hline- & - & $\% 100$ & 12 & 47 & - & - & $\% 100$ & 12 & 9 \\
\hline- & - & $\% 100$ & 12 & 48 & - & - & $\% 100$ & 12 & 10 \\
\hline- & - & $\% 100$ & 12 & 49 & - & - & $\% 100$ & 12 & 11 \\
\hline- & - & $\% 100$ & 12 & 50 & $\% 16.7$ & 2 & $\% 83.3$ & 10 & 12 \\
\hline- & - & $\% 100$ & 12 & 51 & - & - & $\% 100$ & 12 & 13 \\
\hline- & - & $\% 100$ & 12 & 52 & - & - & $\% 100$ & 12 & 14 \\
\hline- & - & $\% 100$ & 12 & 53 & - & - & $\% 100$ & 12 & 15 \\
\hline- & - & $\% 100$ & 12 & 54 & - & - & $\% 100$ & 12 & 16 \\
\hline- & - & $\% 100$ & 12 & 55 & - & - & $\% 100$ & 12 & 17 \\
\hline- & - & $\% 100$ & 12 & 56 & - & - & $\% 100$ & 12 & 18 \\
\hline- & - & $\% 100$ & 12 & 57 & $\% 83.3$ & 10 & $\% 16.7$ & 2 & 19 \\
\hline- & - & $\% 100$ & 12 & 58 & $\% 83.3$ & 10 & $\% 16.7$ & 2 & 20 \\
\hline- & - & $\% 100$ & 12 & 59 & $\% 83.3$ & 10 & $\% 16.7$ & 2 & 21 \\
\hline- & - & $\% 100$ & 12 & 60 & $\% 83.3$ & 10 & $\% 16.7$ & 2 & 22 \\
\hline- & - & $\% 100$ & 12 & 61 & - & - & $\% 100$ & 12 & 23 \\
\hline- & - & $\% 100$ & 12 & 62 & - & - & $\% 100$ & 12 & 24 \\
\hline- & - & $\% 100$ & 12 & 63 & - & - & $\% 100$ & 12 & 25 \\
\hline- & - & $\% 100$ & 12 & 64 & & - & $\% 100$ & 12 & 26 \\
\hline- & - & $\% 100$ & 12 & 65 & - & - & $\% 100$ & 12 & 27 \\
\hline- & - & $\% 100$ & 12 & 66 & $\% 83.3$ & 10 & $\% 16.7$ & 12 & 28 \\
\hline- & - & $\% 100$ & 12 & 67 & - & - & $\% 100$ & 12 & 29 \\
\hline
\end{tabular}


مجلة البحوث في مجالات التربية النوعية

\begin{tabular}{|c|c|c|c|c|c|c|c|c|c|}
\hline \multicolumn{4}{|c|}{ أهمية المهارة الفرعية بالنسبة للفئة المستهدفة } & \multirow{3}{*}{ p } & \multicolumn{4}{|c|}{ أهمية المهارة الفرعية بالنسبة للفئة المستهدفة } & \multirow{3}{*}{ r } \\
\hline \multicolumn{2}{|c|}{ غير مهمة } & \multicolumn{2}{|c|}{ مهمة } & & \multicolumn{2}{|c|}{ غير مهمة } & \multicolumn{2}{|c|}{ مهمة } & \\
\hline النسبة & تكرار & النسبة & تكرار & & النسبة & تكرار & النسبة & تكرار & \\
\hline- & - & $\% 100$ & 12 & 68 & - & - & $\% 100$ & 12 & 30 \\
\hline- & - & $\% 100$ & 12 & 69 & $\% 83.3$ & 10 & $\% 16.7$ & 2 & 31 \\
\hline- & - & $\% 100$ & 12 & 70 & $\% 83.3$ & 10 & $\% 16.7$ & 2 & 32 \\
\hline- & - & $\% 100$ & 12 & 71 & - & - & $\% 100$ & 12 & 33 \\
\hline- & - & $\% 100$ & 12 & 72 & $\% 83.3$ & 10 & $\% 16.7$ & 2 & 34 \\
\hline- & - & $\% 100$ & 12 & 73 & - & - & $\% 100$ & 12 & 35 \\
\hline- & - & $\% 100$ & 12 & 74 & $\% 83.3$ & 10 & $\% 16.7$ & 2 & 36 \\
\hline- & - & $\% 100$ & 12 & 75 & - & - & $\% 100$ & 12 & 37 \\
\hline & & & & & - & - & $\% 100$ & 12 & 38 \\
\hline
\end{tabular}

وبعـد إجـراء التعـديلات المقترحسة على قائمـة المهارات أصـبحت القائمسة في

صـورتها النهائيـة مشـتملة على (66) مهارة فرعيـة موزعـة على (9) مهـارات رئيسـة

$$
\text { (ملحق2). }
$$

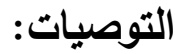

يوصسي البـاحثنون بالإسـتفادة مسن قائمسة مهـارات إنتـاج الـدروس الإكترونيـة

بإسـتخدام برنـامج Articulate ي storyline3 في مراكز إنتـاج المقـررات والـدروس

الإلكترونية بالجامعات والمؤسسات المعنية بهذا الغرض.

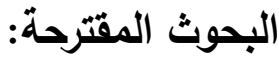

يقترح الباحثون تطوير قائمة مهارات لتصميم السيناريوهات التعليمية المُعدة

$$
\text { الإنتاج الدروس الإلكترونية. }
$$




\section{المراجع والمصادر}

أحمد حسين اللقاني (1999). معجم المصطلحات التزبوية المعرفة في المناهج وطرق التنريس،ط2،

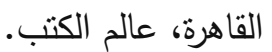

أحمد محمد أحمد محمد (2017). المهارات اللازمة لإنتاج الدروس الإلكترونية التفاعلية متعددة

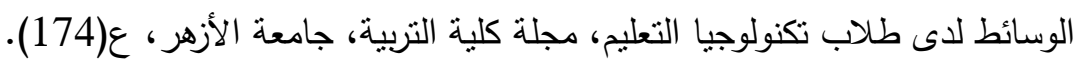

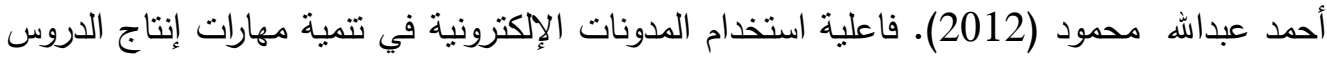

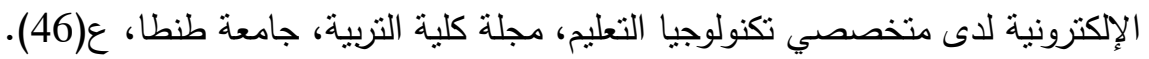

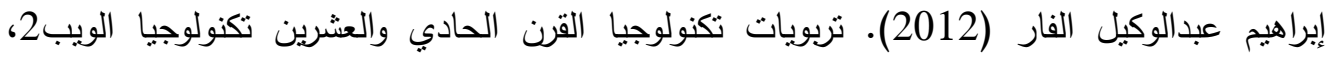
طنطا، الدلتا لتكنولوجيا الحاسبات. إبراهيم عبدالوكيل الفار، سعاد أحمد شاهين (2001). الددرسة الإلكترونية رؤى جديدة لجيل جديد،

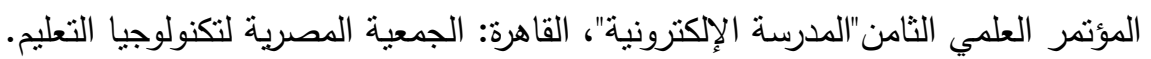
السعيد السعيد عبدالرازق (2011). تصميم العروض التقديمية متعددة الوسائط على شبكة الإنترنت،

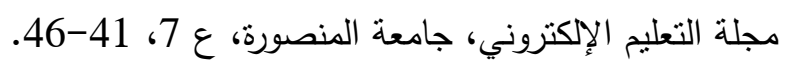

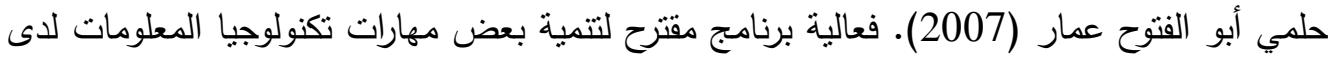

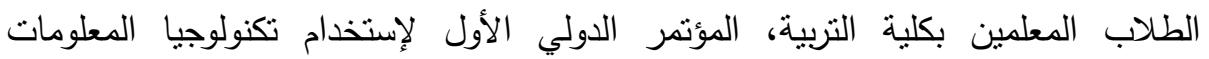

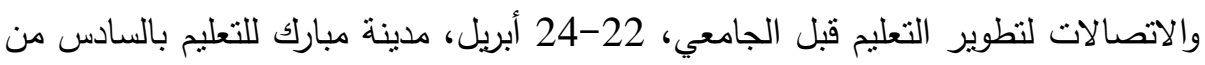
اكتوبر - الأن

زهير ناجي خليف (2015). تعلم برنامج articulate storyline لبناء المحتوى الإككتروني التفاعلي، التها، جامعة انديانا، الولايات المتحدة الأمريكية متاح من خلال الرابط: نائ لئاء http://www.alaws2020.com/arts.pdf زينب محمد أمين (2008). نظم إدارة التعلم وعلاقتها بمهارات إنتاج الدروس الإلكترونية وإدارة الوقت

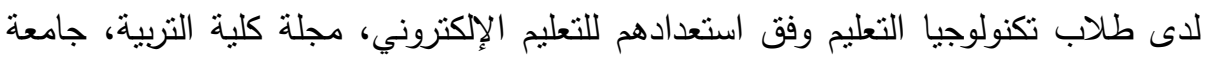

$$
\text { الأزهر ، ع (136). }
$$

سلامة عبد العظيم حسن ، وأثنواق عبدالجليل علي (2008). الجودة في التعلم الإلكتروني مفاهيم نظرية وخبرات عالمية، الأسكندرية، دار الجامعة الجديدة.

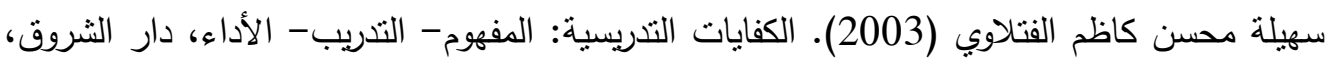
عمان ، الأردن. فؤاد عبد اللطيف أبو حطب، آمال مُختار صادق (1999). سيكولوجية التعلم، القاهرة: الدار الدولية، $.250-248$ كوثر حسين كوجك (2001). اتجاهات حديثة في المناهج وطرق التنريس، عالم الكتب. 
مجلة البحوث في مجالات التربية النوعية

محمد عطية خميس (2001). أخصائي تكنولوجيا التعليم في المدرسة الإككترونية، المؤتمر العلمي الثامن"الددرسة الإككترونية"، القاهرة، الجمعية المصرية لتكنولوجيا التعليم.

(2009). تكنولوجيا التعليم والتعلم، ط2، دار السحاب للطباعة والنشر الفئر

$$
\text { والتوزيع. }
$$


مجلة البحوث فى مجالات التربية النوعية

\section{ملاحق البحث}

ملحق (1) قائمة باسماء السادة المحكمين

\section{الوظيفة وجهة العمل}

\begin{tabular}{|c|c|c|}
\hline أستاذ تكنولوجيا التعليم المساعد،الجامعة المصرية للتعليم الإكتروني. & أ.م.د/ محمد السيد النجار & 1 \\
\hline أستاذ تكنولوجيا التعليم المساعد، كلية التربية، جامعة حلوان. & أ.م.د/ وائل رمضان عبدالحميد يوسف & 2 \\
\hline أستاذ تكنولوجيا التعليم المساعد، كلية الدراسات العليا للتربية، جامعة & أ.م.د /ممدوح سالم الفقي & 3 \\
\hline أستاذ تكنولوجيا التعليم المساعد، كلية التربية، جامعة القاهرة. & أ.م.د /سلوى محمود المصري & 4 \\
\hline مدير إدارة التخطيط والتطوير بالإدارة العامة للتعليم الإلكتروني. & د/شريف إبراهيم الجمل & 5 \\
\hline مدرس تكنولوجيا التعليم،كلية الدراسات العليا للتربية- & د/حمزة محمد إبراهيم القصبي & 6 \\
\hline مطور مقررات إلكترونية بمركز إنتاج المقررات جامعة المنصورة. & نرمين محمود محمد & 7 \\
\hline مطور مقررات إلكترونية بمركز إنتاج المقررات جامعة المنيا. & محمد مددوح عبد الحكيم & 8 \\
\hline مطــــر مقــررات إلكترونيــة بــالمركز القــومي لإنتـــاج المقـررات & ماريان ماهر & 9 \\
\hline 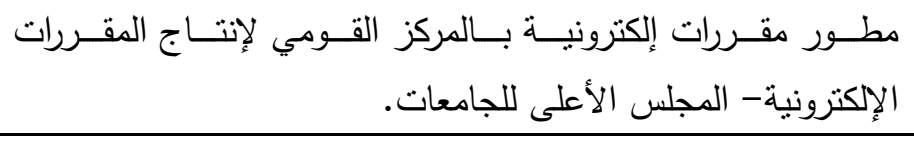 & نعمة عجيب محمد & 10 \\
\hline قسم إنتاج البرمجيات بوزارة التربية والتعليم. & سيد أحمد السيد & 11 \\
\hline أخصائي تكنولوجيا التعليم- مركز التطوير التكنولوجي بالدقهلية. & عمرو حمودة عبد الحميد & 12 \\
\hline
\end{tabular}


مجلة البحوث فى مجالات التربية النوعية

\section{ملحق (2)}

Articulate قائمة مهارات إنتاج الاروس الإكترونية في صورتها النهائية باستخدام برنامج

\section{Storyline3}

\section{المهارات الرئيسة وإجراءاتها الفرعية}

\begin{tabular}{|c|c|}
\hline \multicolumn{2}{|c|}{ أولاً - مهارات التعامل مع الشرائح: } \\
\hline يضيف مشهد Scene داخل البرنامج. & 1 \\
\hline يضيف شريحة Slide داخل البرنامج. & 2 \\
\hline يحدد الشريحة الرئيسة Master. & 3 \\
\hline يُعيد تسمية 3 شرائح في الدرس. & 4 \\
\hline يضيف شرائح فرعية للارس. & 5 \\
\hline يُغير إعدادات حجم الثريحة. & 6 \\
\hline يستخدم التصميم اليُخصص للشريحة. & 7 \\
\hline يضيف الحركة الانتقالية للشرائح. & 8 \\
\hline \multicolumn{2}{|c|}{ ثانياً - مهارات التعامل مع النصوص } \\
\hline يستخدم خطوطاً سهلة القراءة ومُريحة للعين. & 9 \\
\hline يميز بين العناوين الرئيسية والفرعية من حيث الحجم. & 10 \\
\hline يظهر التباين بين لون خط النصوص ولون الخلفية. & 11 \\
\hline يستخدم نمطين من أنواع الخطوط . & 12 \\
\hline يدرج مربع نص داخل الشريحة. & 13 \\
\hline يُحاذي في النص (يمين، وسط، شمال). & 14 \\
\hline يُضيف تعداد نقطي ورقمي للنص. & 15 \\
\hline يعين خلفية لمربع النص. & 16 \\
\hline يختار حدود كاملة لمربع النص. & 17 \\
\hline يضيف حركة واحدة على الأقل للنص. & 18 \\
\hline \multicolumn{2}{|c|}{ ثالثًا- مهارات التعامل مع الصور والرسومات } \\
\hline يدرج صورة داخل الثريحة. & 19 \\
\hline يُضيف إطار للصورة. & 20 \\
\hline يُغير حجم الصورة. & 21 \\
\hline 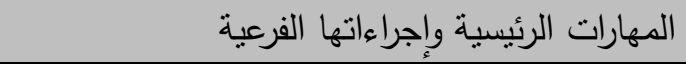 & r \\
\hline
\end{tabular}


مجلة البحوث في مجالات التربية النوعية

\begin{tabular}{|c|c|}
\hline يضيف نأثثرات مُختلفة للصور . & 22 \\
\hline يضيف شخصية "Character" واحدة على الأقل داخل الثريحة. & 23 \\
\hline \multicolumn{2}{|c|}{ رابعًا- مهارات التعامل مع مقاطع الصوت والفيديو } \\
\hline يدرج مقطعًا صوتيًا داخل الثريحة. & 24 \\
\hline يدرج مقطع فيديو داخل الثريحة. & 25 \\
\hline يُضيف أدوات للتحكم في عرض لقطات الفيديو. & 26 \\
\hline يضبط التزامن بين الصوت والصورة. & 27 \\
\hline \multicolumn{2}{|c|}{ خامسًا - مهارات التعامل مع الملفات الخارجية } \\
\hline يضيف ارتباطًا تشعبيًا داخل الثريحة. & 28 \\
\hline يضيف ثناثة أزرار للشرائح (السابق، الثاثشة الرئيسية، التالي). & 29 \\
\hline ليُغير في تتسيقات نمط الأزرار. & 30 \\
\hline يدرج ملف PowerPoint واحداً على الأقل. & 31 \\
\hline يدرج ملف Articulate واحداً على الأقل. & 32 \\
\hline يدرج رابطًا لموقع إنترنت واحدًا على الأقل داخل الثريحة الواحدة. & 33 \\
\hline \multicolumn{2}{|c|}{ سادسًا - مهارات التعامل مع الأشكال والكائنات التفاعلية } \\
\hline يضيف شكلاً داخل الشريحة. & 34 \\
\hline يُغير لون الثكل داخل الثريحة. & 35 \\
\hline يضيف كائنًا داخل الشريحة. & 36 \\
\hline يضيف حركة على الكائن. & 37 \\
\hline يتحكم في مدة عرض الكائن. & 38 \\
\hline يُعيد تسمية الكائنات على شريط الزمن "Time line". & 39 \\
\hline يتحكم في تأمين الكائنات على شريط الزمن "Time line" . & 40 \\
\hline يضيف مشغل "Triggers" للشريحة. & 41 \\
\hline يضيف العلامات "Markers". & 42 \\
\hline يضيف نقاطاً ساخنة "Hot-spot". & 43 \\
\hline
\end{tabular}




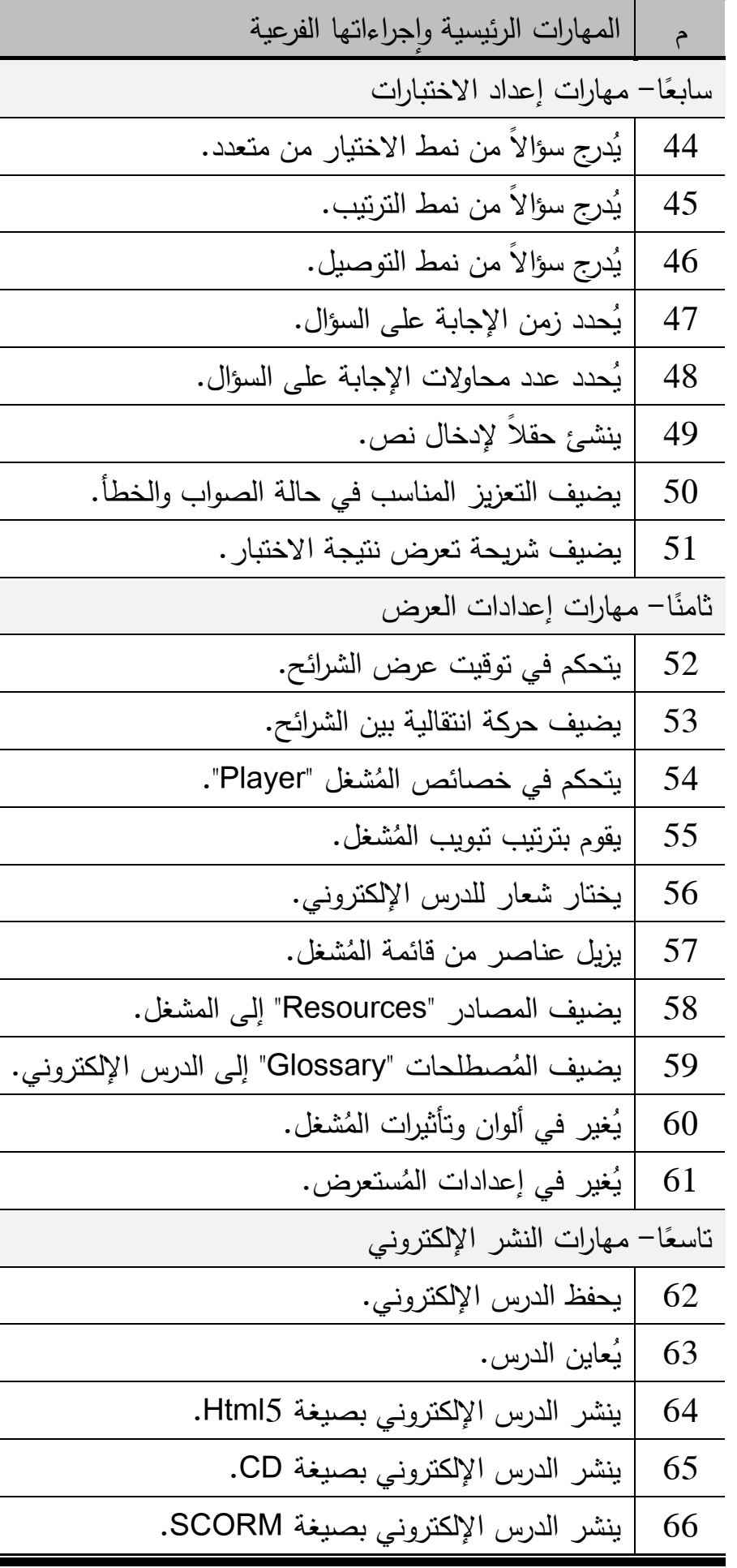

